\begin{tabular}{ccc}
\hline & International Journal of Engineering \& Technology, $7(2.2)(2018) 108-111$ \\
SPC & International Journal of Engineering \& Technology \\
\hline
\end{tabular}

\title{
Deflection prediction of cantilever concrete beam using adaptive fuzzy inference system
}

\author{
Sujiati Jepriani ${ }^{1 *}$, Ibayasid ${ }^{1}$, Aji Prasetya Wibawa ${ }^{2}$, Leonel Hernandez ${ }^{3}$ \\ ${ }^{1}$ Department of Civil Engineering, State Polytechnic of Samarinda, East Kalimantan, Indonesia \\ ${ }^{2}$ State University of Malang, Malang, East Java, Indonesia \\ ${ }^{3}$ Institución Universitaria ITSA, Colombia \\ *Corresponding author_E-mail: sujiati_jepriani@polnes.ac.id,yasid@polnes.ac.id
}

\begin{abstract}
The cantilever concrete beam is a beam made of concrete that is only supported or clamped at one end and the other end free or without the pedestal. The measure to which a structural member gets deviated from the initial position is called deflection. All the internal forces of cantilever beam serve to hold all the external forces due to the load so that the structure remains balanced. While the beam gets deflected under the loads, bending occurs in the same plane due to which stresses are developed. From the moment balance formula after integrated and solved with required boundary conditions, we get the downward deflection of beam. Fuzzy logic provides an inference structure that enables appropriate human reasoning capabilities. FIS (Fuzzy Inference System) is a system that processes the mapping formulation of a given input to produce an output using Fuzzy Logic. By using randomized data for all the variables of deflection formula within their respective ranges as training data, the FIS will be able to predict deflection of cantilever concrete beam after going through the training process adaptively.
\end{abstract}

Keywords: cantilever of concrete beam, deflection, Fuzzy Logic, FIS.

\section{Introduction}

The concrete is the most widely used construction material in the world after water. Many advances in all areas of concrete technology include materials, mixed proportional, recyclable, structural design, durability requirements, testing. High-performance concrete is essentially composed of the same material as in conventional concrete but its proportions are designed to provide the strength and durability required by the structure of a building. Beams and columns are the most regular parts of a building structure that must meet the possible state. The planned structure should be checked for minimal conditions on the deflection and width of the gap[1], [2].

The cantilever beam is a beam that is only supported or clamped at one end and the other end free or without pedestal. This construction is often found on the part of a building construction. Cantilever concrete beams are cantilevered beams made of concrete. One of the properties of the concrete is the compressive strength ( $\mathrm{MPa}$ $($ Mega Pascal $)=\mathrm{N} / \mathrm{mm} 2)$ defined as the maximum force $(\mathrm{N})$ applied to the concrete cross-sectional area (mm2). Another property of the concrete is the modulus of elasticity, which is defined as a measure of material stiffness or resistance to deformation. The modulus of elasticity is determined by changes in stress to strain within its elasticity limit. The modulus of elasticity of concrete will increase along with the increase of concrete compressive strength. The measure to which a structural member gets deviated from the initial position is called deflection. The deflected distance of a member under a load is directly related to the slope of the deflected shape of the member under that load. While the beam gets deflected under the loads, bending occurs in the same plane due to which stresses are developed[3].
Predicting beam behavior and elements of deflection is an important task for the structural engineer; the parameters that include deflection among others are a concrete compressive strength, web reinforcement ratio, and modulus. Prediction using ANFIS method[4]. Multiphysics COMSOL method on validation of concrete deflection analysis [5], strengthening of concrete beams using basalt FRP bars [6], and research using the continuous beam method is preferred because of the ease of economic side, contraction joints and redistribution moment [7], as well as research that performs performance evaluation of reinforced concrete structures with fuzzy logic approach [8].

This study applies the adaptive FIS concept to predict the deflection of cantilever concrete beam based on deflection formula.

The aim of this study is to test the performance of adaptive FIS concepts to predict cantilever concrete beam deflection using random values for each variable of deflection formula in the range of values that comply with Indonesian National Standard (SNI 2847: 2013).

\section{Experimental Details}

\subsection{The cantilever beam concept}

First, a uniform rectangular cross-sectional beam of linear elastic isotropic homogeneous material has been considered. The beam is taken massless and inextensible hence have developed no strains. It is subjected to a vertical point load at the tip of its free end. Similarly, it is done with the same value of the uniformly distributed load and uniformly varying load over the whole span. Generally, the cantilever beam is shown in Figure 1. 


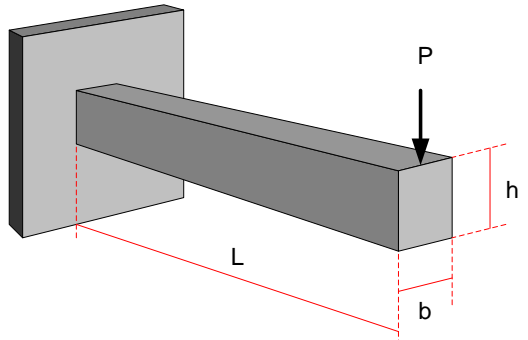

Fig. 1: Cantilever Beam.

From Figure 2 show that all the internal forces serve to hold all the external forces due to the load so that the structure remains balanced. The bending moment is expressed by [1]

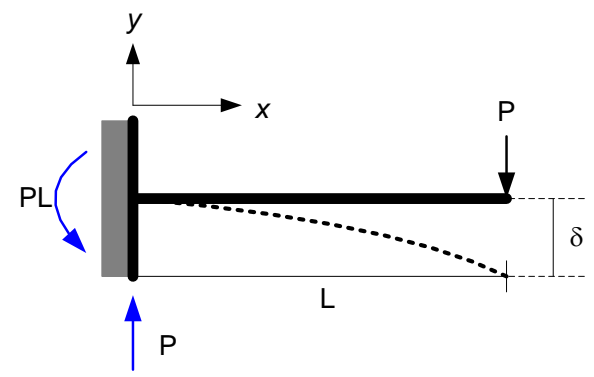

Fig. 2: Free body diagram

$M=E . I \cdot \frac{d^{2} y}{d x^{2}}$

In Eq. (1), $E$ is the modulus of elasticity, and $I$ is the inertial moment of beam which expressed by:

$I=\frac{1}{12} \cdot b \cdot h^{3}$

Where $b$ is width of beam, $h$ is height of beam. The balance of the moment is expressed by:

$$
\begin{aligned}
& M=-P . L+P . x \\
& \text { E.I. } \frac{d^{2} y}{d x^{2}}=-P . L+P . x
\end{aligned}
$$

On integrating and solving the Eq. (3) with required boundary conditions, we get the downward deflection of beam as:

$$
\delta=y=-\frac{P . L . x}{2 . E . I}+\frac{P . x^{3}}{6 . E . I}
$$

With a concentrated load at the free end so that $x=L$ then there will be the maximum deflection which expressed by:

$\delta_{\max }=-\frac{P \cdot L^{3}}{3 \cdot E \cdot I}$

\subsection{Fuzzy Logic}

Fuzzy logic provides an inference structure that enables appropriate human reasoning capabilities. The theory of fuzzy logic provides an inference mechanism under cognitive uncertainty. The utility of fuzzy sets lies in their ability to model uncertain or ambiguous data. Fuzziness in a fuzzy set is characterized by its Membership Functions [9], [10], [12], [13]. The one of several of Membership Functions (MF) is Triangular MF as shown in Figure 3 which mathematically expressed by:

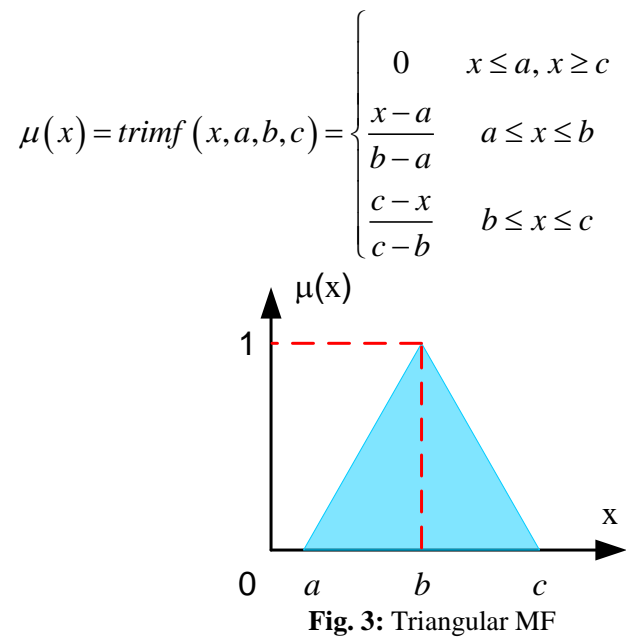

FIS is a system that processes the mapping formulation of a given input to produce an output using Fuzzy Logic. FIS is shown in Figure 4. There are various methods of defuzzification; one of the most popular is the centroid method, which returns the center of the area under the curve.

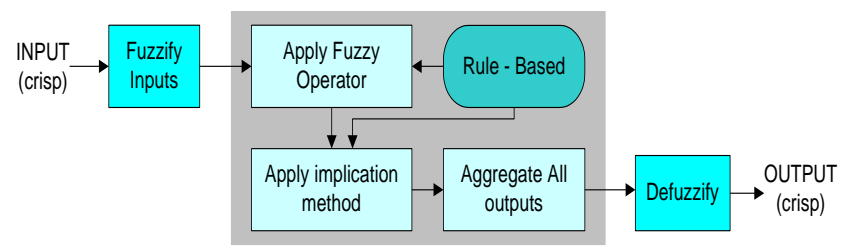

Fig. 4: Fuzzy Inference System

For a Fuzzy Set $X$ with a finite universe of discourse, the centroid method is expressed by:

$x_{c}=\left(\sum_{i=1}^{n} x_{i} \cdot \mu\left(x_{i}\right)\right) / \sum_{i=1}^{n} \mu\left(x_{i}\right)$

where $x_{c}$ is the centroid value, $x_{i}$ is $x$ value of $i$ th point correspond to $\mu\left(x_{i}\right)$ from the aggregation result, $\mu\left(x_{i}\right)$ is the degree of membership (fuzzy number) of $x_{i}, n$ is the number of $\left(x_{i}, \mu\left(x_{i}\right)\right)$ pairs in the curve.

For example, there are two inputs $(A$ and $B)$ and one output $(C)$ where all three variables have linguistic variables (Low, Medium, High) and have the same fuzzy set as shown in Figure 5. If $A(x)=$ $20, B(x)=65$ have two rules then FIS process is shown in Figure 6 .

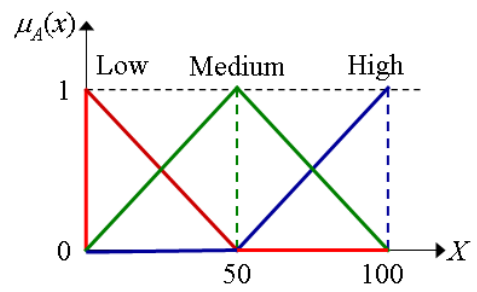

Fig. 5: Fuzzy Set (Triangular MF)

In this study, concentrated load $(P)$ is in the range $[10000,30000]$ $\mathrm{N}$, the compressive strength of normal concrete (fc) in the range [20, $30] \mathrm{MPa}$, length of the cantilever beam $(L)$ in range $[1000,4000] \mathrm{m}$. The Indonesian National Standard (SNI 2847:2013) article 9.5.2.1 states that for cantilever beams required minimum $L / 8$ so that for $L_{\max }=4000$ obtained $h_{\min }=500$. For this reason, width $(b)$ and height (h) of cantilever beam are planned in the range [500 .. 1000] $\mathrm{mm}$. Modulus of elasticity of normal concrete $(E)$ is using SNI 2847:2013 articles 8.5.1 [11] that is $E=4700 \sqrt{f_{c}}$. Maximum deflection will be obtained if $P=30000 \mathrm{~N}$ (High), $f_{\mathrm{c}}=20 \mathrm{MPa}$ (Low), $L=4000 \mathrm{~mm}$ (High), $b=500 \mathrm{~mm}$ (Low), $h=500 \mathrm{~mm}$ (Low), where 
$E=21019 \mathrm{MPa}, I=5208333333 \mathrm{~mm}^{4}$, and $\delta=-5.8461 \mathrm{~mm}$. Therefore the deflection of cantilever concrete beam is planned in the positive range $[0,5.8461] \mathrm{mm}$. If three linguistic variables are used then the rule for maximum deflection is expressed by:

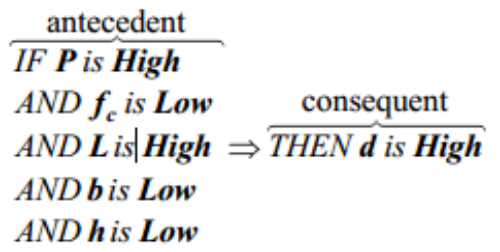

The rule can be built from the calculation with several of data, which then arranged into Rule-Based. By using randomized data for each $P, f_{c}, b, h$, and $L$ within their respective ranges as training data, the FIS will be able to predict deflection of cantilever concrete beam after going through the training process. The training process is shown in Figure 7. The performance function of the training results using MAE (Mean Absolute Error) expressed by Eq. (8).

$M A E=\frac{1}{N} \sum_{i=1}^{N} a b s\left(y\left(t_{i}\right)-y_{\text {fuzzy }}\left(t_{i}\right)\right)$

where $N$ is the number of training data, $y\left(t_{i}\right)$ is the ith training target, $y_{f u z z y}\left(t_{i}\right)$ is the ith output of FIS. Implementation of FIS is done by using Matlab programming tool. In this study, the FIS uses 5 linguistic variables for initialization and MAE target $e(t)=0.015$.
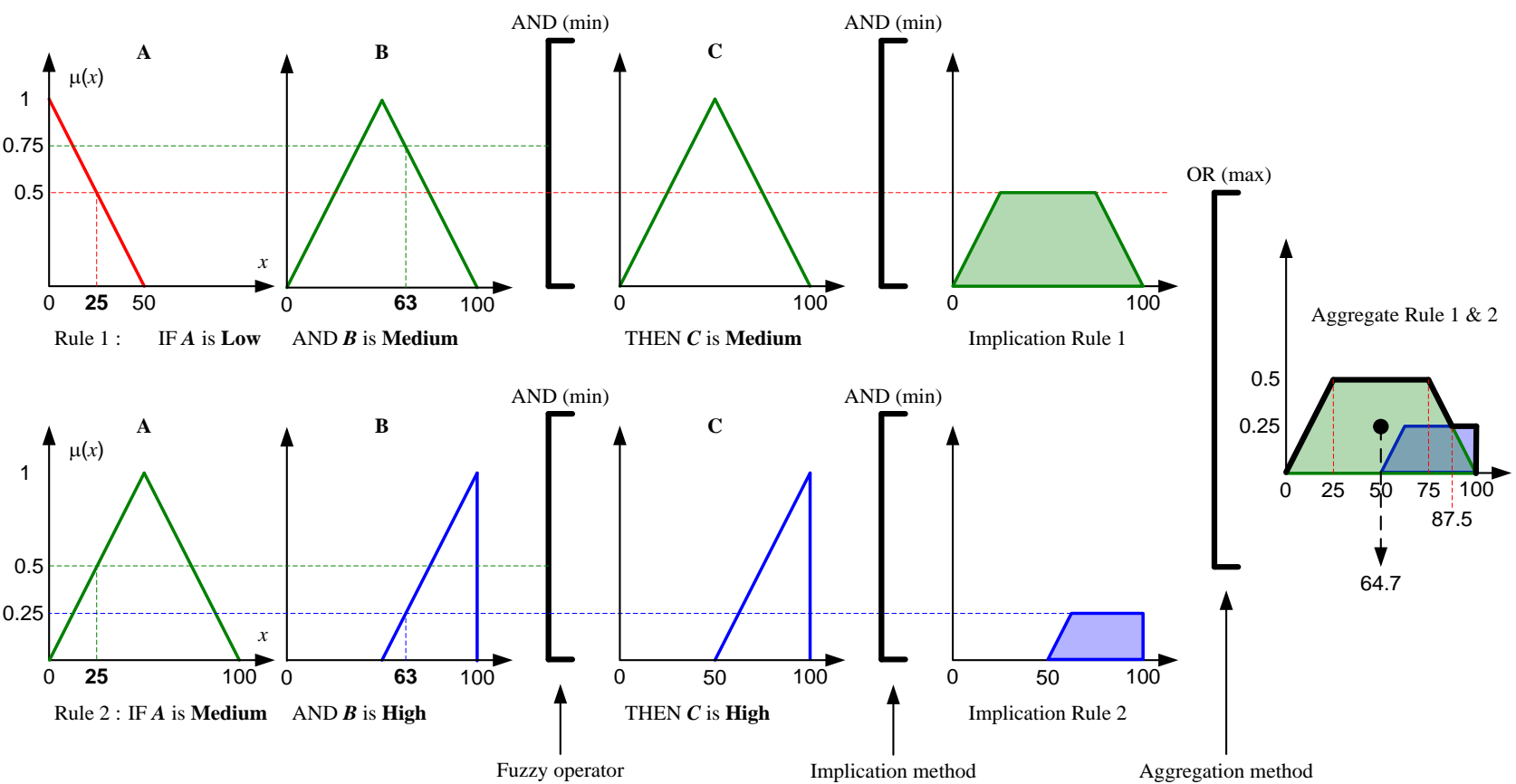

Fig. 6: Fuzzy Inference System process

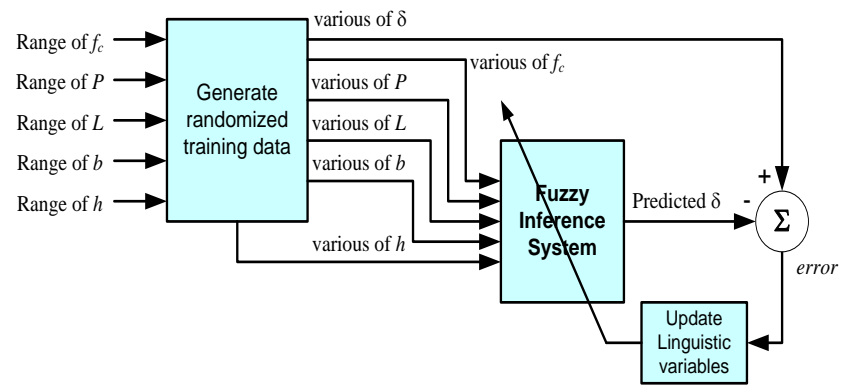

\section{Result and Discussion}

The training results using 245 random data are shown in Figure 8. Final MAE is 0.0148 with the number of linguistic variables of 81 . The validation of the training results is done using 10 test data as shown in Table 1. The validation results are shown in Figure 9 with MAE of 0.0178

Fig. 7: Training process for modeling of deflection prediction using FIS

Table 1: Test data

\begin{tabular}{|c|c|c|c|c|c|c|c|c|}
\hline \multirow{2}{*}{ No. Data } & \multirow{2}{*}{ fc (MPa) } & \multirow{2}{*}{$\mathrm{P}(\mathrm{N})$} & \multirow{2}{*}{$\mathrm{L}(\mathrm{mm})$} & \multirow{2}{*}{$\mathrm{b}(\mathrm{mm})$} & \multirow{2}{*}{$\mathrm{h}(\mathrm{mm})$} & \multicolumn{2}{|c|}{ Deflection (mm) } & \multirow{2}{*}{$\begin{array}{l}\text { Absolute er- } \\
\text { ror }\end{array}$} \\
\hline & & & & & & calculated & Predicted & \\
\hline 1 & 20 & 10000 & 2000 & 750 & 1000 & 0.0203 & 0.0150 & 0.0053 \\
\hline 2 & 25 & 30000 & 1000 & 750 & 750 & 0.0161 & 0.0113 & 0.0048 \\
\hline 3 & 30 & 20000 & 4000 & 750 & 1000 & 0.2652 & 0.2938 & 0.0286 \\
\hline 4 & 20 & 20000 & 4000 & 750 & 750 & 0.7699 & 0.8003 & 0.0305 \\
\hline 5 & 25 & 20000 & 1000 & 750 & 500 & 0.0363 & 0.0113 & 0.0250 \\
\hline 6 & 20 & 30000 & 2000 & 750 & 500 & 0.4872 & 0.5056 & 0.0185 \\
\hline 7 & 20 & 10000 & 4000 & 1000 & 750 & 0.2887 & 0.2938 & 0.0051 \\
\hline 8 & 20 & 10000 & 1000 & 1000 & 1000 & 0.0019 & 0.0113 & 0.0094 \\
\hline 9 & 30 & 10000 & 2000 & 500 & 500 & 0.1989 & 0.2134 & 0.0145 \\
\hline \multirow[t]{2}{*}{10} & 20 & 30000 & 2000 & 1000 & 1000 & 0.0457 & 0.0819 & 0.0362 \\
\hline & & & & & & & MAE & 0.0178 \\
\hline
\end{tabular}




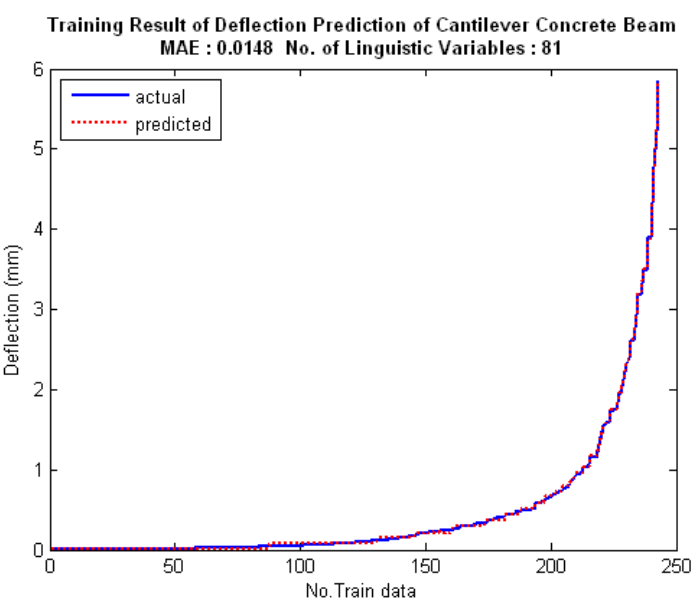

Fig. 8: Training result

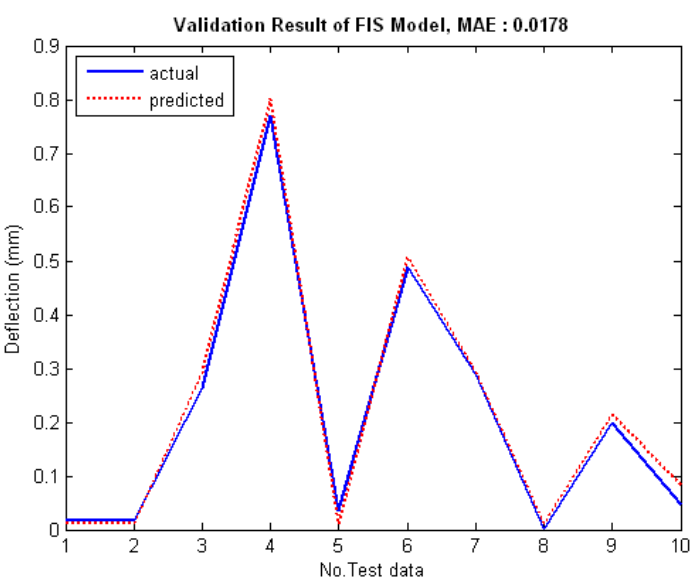

Fig. 9: Validation result

\section{Conclusion}

From the results of this study indicates that with an MAE target of 0.015 , the FIS model can predict a cantilever beam deflection with MAE of 0.0148. Validation of training results using 10 test data obtained MAE of 0.0178. From this result, it can be concluded that the FIS model that has been made is able to predict the deflection of cantilever concrete beam well enough. The proposed model looks like the approximation of deflection of the cantilever beam formula as shown in equation (5). For the future, the proposed model can be used to predict each of the cantilever beam deflection variables needed for the design. For example, if we need to predict width and height of cantilever beam with $P, f_{c}, L$, and $\delta$ are known then we need to rearrange rule based on the inverse mode as follows:

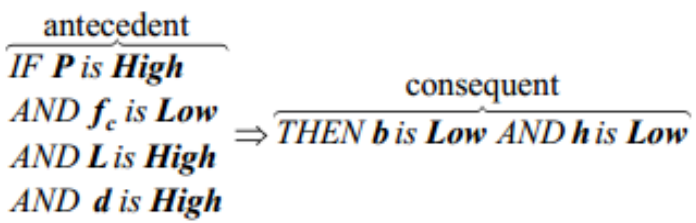

\section{Acknowledgement}

The authors would like to express their heartfelt thanks to the Modern Computing Research Center, Department of Information Technology, State Polytechnic of Samarinda for providing all their support.

\section{References}

[1] S. Sharmila and P. Chandrasekaran, "Performance evaluation of high-performance concrete beams under cyclic loading," Int. J. Eng. Technol., vol. 7, pp. 71-73, 2018.

[2] G. PapaRao and D. S. R. C. Murty, "Influence of stirrup spacing on shear resistance of reinforced concrete beams," Mag. Concr. Res., vol. 65, no. 14, pp. 829-836, 2013.

[3] A. K. Samal and T. E. Rao, "Analysis of Stress and Deflection of Cantilever Beam and its Validation Using ANSYS," Int. J. Eng. Res. Appl., vol. 6, no. 1, pp. 119-126, 2016.

[4] M. Mohammadhassani, H. Nezamabadi-Pour, M. Jumaat, M. Jameel, S. J. S. Hakim, and M. Zargar, "Application of the ANFIS model in deflection prediction of concrete deep beam," Struct. Eng. Mech., vol. 45, no. 3, pp. 319-332, 2013.

[5] S. Singh, S. Padhi, A. A. Patra, and S. Hajra, "Analysis of Stress and Deflection of Cantilever Beam and its Validation Using COMSOL Multiphysics," Int. J. Recent Trends Eng. Res., vol. 2, no. 8, pp. 275-279, 2016.

[6] K. Nasrollahzadeh and M. M. Basiri, "Prediction of shear strength of FRP reinforced concrete beams using fuzzy inference system," Expert Syst. Appl., vol. 41, no. 4, 2013.

[7] J. S. Du, F. T. K. Au, E. K. H. Chan, and L. Liu, "Deflection of unbonded partially prestressed concrete continuous beams," Eng. Struct., vol. 118, no. July, pp. 89-96, 2016.

[8] F. G. K. Pakdamar, "Fuzzy Logic Approach In The Performance Evaluation Of Reinforced Concrete Structures (Flexible Performance)," World Conf. Earthq. Eng., 2008.

[9] I. The Mathworks, Fuzzy Logic Toolbox ${ }^{\text {TM }}$ User 's Guide. 2014.

[10] S. N. Sivanandam, S. Sumathi, and S. N. Deepa, Introduction to Fuzzy Logic using MATLAB, 1st ed. Springer-Verlag Berlin Heidelberg, 2007.

[11] I. N. Standard, Requirement of Concrete Structures for Buildings. 2013.

[12] Purnawansyah, Haviluddin, A. F. O. Gafar, and I. Tahyudin, "Comparison between K-Means and Fuzzy C-Means Clustering in Network Traffic Activities," in 2017 International Conference on Management Science and Engineering Management (ICMSEM), 2017.

[13] Purnawansyah and Haviluddin, "K-Means Clustering Implementation in Network Traffic Activities," in 2016 International Conference on Computational Intelligence and Cybernetics, Makassar, Indonesia, 2016, pp. 51-54. 